\title{
Spontaneous Bilateral Tubal Ectopic Pregnancy: Incidental Finding During Laparoscopy - Brief Report and Review of Literature
}

\author{
Spontane bilaterale Extrauteringravidität: Zufallsbefund im Rahmen \\ einer Laparoskopie - Kurzbericht und Literaturübersicht
}

Authors

Affiliation

\author{
S. Hoffmann, H. Abele, C. Bachmann
}

Department of Obstetrics and Gynecology, Tübingen University Hospital, Tübingen
Key words

- assisted reproductive technology (ART)

- ectopic pregnancy

- infertility

Schlüsselwörter

- assistierte Reproduktionstechniken (ART)

- Extrauteringravidität

- Unfruchtbarkeit

\section{received 21.8.2015 \\ revised 29.11.2015 \\ accepted 29.11.2015}

\section{Bibliography}

Dol http://dx.doi.org/ 10.1055/s-0041-110394

Geburtsh Frauenheilk 2016; 76: 413-416 (c) Georg Thieme

Verlag KG Stuttgart · New York · ISSN 0016-5751

\section{Correspondence}

C. Bachmann, MD

Department of Obstetrics

and Gynecology, Tübingen

University Hospital

Calwer Straße 7

72070 Tübingen

cornelia.bachmann@

med.uni-tuebingen.de

\section{Abstract}

$\nabla$

Objective: Bilateral tubal ectopic pregnancies are rare; the reported incidence is only 1 in 200000 pregnancies. Detecting bilateral tubal ectopic pregnancy is urgent because of the associated morbidity and mortality. The appropriate fertility-preserving surgery must also be considered, as preservation of both tubes is presumed to offer better fertility prospects.

Case Report: A 39-year-old gravida 2, para 1 presented with vaginal bleeding at $8+4$ weeks of gestation. An approximately $18 \mathrm{~mm}$ adnexal mass in the right fallopian tube was detected on ultrasound. Laparoscopy was performed because ectopic pregnancy was suspected. This suspicion was confirmed during laparoscopy; the right fallopian tube was found to contain a mass measuring $20 \mathrm{~mm}$ in the isthmic part. Ultrasound of the left fallopian tube also showed a mass in the ampullary region (diameter: $10 \mathrm{~mm}$ ), also suspicious for ectopic pregnancy. Bilateral salpingotomy was performed laparoscopically. Pathological examination confirmed the diagnosis.

Conclusions for Practice: Although ectopic tubal pregnancy is seen more often after assisted reproductive techniques, bilateral spontaneous ectopic pregnancies must also be considered in other cases. Laparoscopic surgery is effective to confirm the diagnosis and treat heterotopic pregnancies. Further studies will be needed to confirm whether unilateral or bilateral conservative fertility-preserving surgery is more appropriate.

\section{Zusammenfassung \\ $\nabla$}

Zielsetzung: Bilaterale extrauterine Schwangerschaften sind rar und kommen mit einer Häufigkeit von nur 1 auf 200000 Schwangerschaften vor. Wegen der damit verbundenen mütterlichen Morbidität und Mortalität ist ein frühzeitiges Erkennen dringend geboten. Wichtig ist die Wahl des operativen Eingriffs im Hinblick auf weitere Schwangerschaften, da die Erhaltung beider Eileiter sich fertilitätserhaltend auswirken kann.

Fallbericht: Eine 39-jährige II. Gravida/I. Para stellte sich mit vaginaler Blutung in der 8. +4 SSW vor. Bei der Ultraschalluntersuchung wurde eine ungefähr $18 \mathrm{~mm}$ große Masse im rechten Eileiter entdeckt. Der Verdacht einer Tubargravidität lag nahe. Dieser Verdacht wurde in der anschließenden Laparoskopie bestätigt; im isthmischen Abschnitt des rechten Eileiters wurde eine Masse mit einem Durchmesser von $20 \mathrm{~mm}$ gefunden. Der Ultraschall des linken Eileiters zeigte eine Masse im ampullären Teil mit einem Durchmesser von $10 \mathrm{~mm}$, die ebenfalls verdächtig auf eine Tubargravidität war. Eine bilaterale Salpingotomie wurde laparoskopisch durchgeführt. Der pathologische Befund hat die Diagnose bestätigt.

Fazit für die Praxis: Obwohl Extrauteringravidität verstärkt nach assistierten Reproduktionstechniken auftritt, sollte spontane bilaterale Extrauteringravidität auch in anderen Fällen in Betracht gezogen werden. Die Laparoskopie wird zur Bestätigung der Diagnose sowie zur Behandlung heterotoper Schwangerschaften eingesetzt. Weitere Studien sind nötig, um festzustellen, ob sich ein einseitiger oder ein bilateraler konservativer Eingriff besser zum Fertilitätserhalt eignet. 


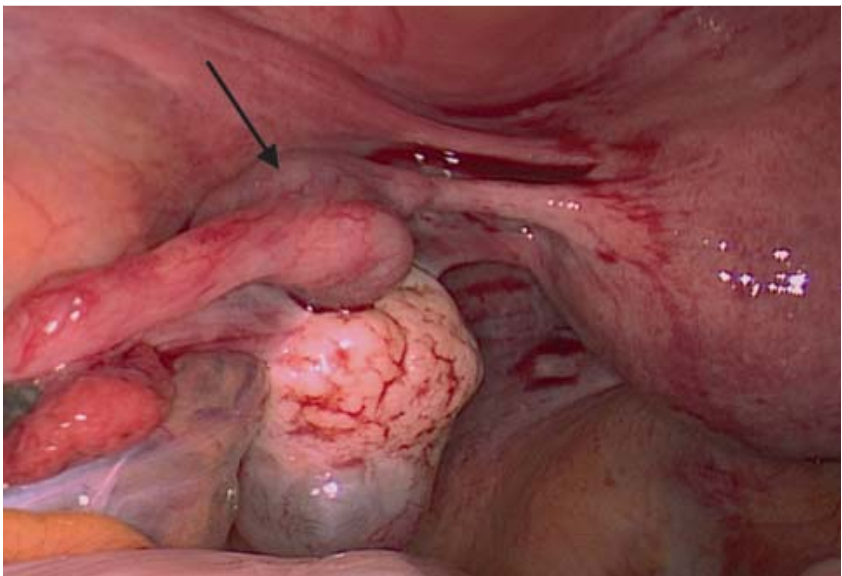

Fig. 1 Findings in the left fallopian tube $(\uparrow)$ of our patient during laparoscopy (UFK Tübingen).

\section{Introduction}

$\nabla$

Spontaneous bilateral tubal pregnancies without previous induction of ovulation are very rare, with an estimated incidence of 1 in 725 to 1 in 1580 ectopic pregnancies [1]. In rare cases, the diagnosis is confirmed before surgery. Careful examination of the pelvis, especially of both fallopian tubes, and of the abdomen is necessary to avoid missing bilateral or heterotopic pregnancies. Another important factor to consider in this context is the appropriate fertility-preserving surgery. Despite the potentially increased risks of persistent trophoblast and repeat ectopic pregnancy, salpingotomy is often preferred over salpingectomy because preservation of both tubes is assumed to offer better fertility prospects, although little evidence exists to support this assumption [2].

Detecting bilateral tubal ectopic pregnancy is urgent because of the associated morbidity and mortality $[1,3]$. This brief report aims to facilitate decision making with regard to the surgical management of such cases.

\section{Case Report}

\section{$\nabla$}

We report on a 39-year-old gravida 2, para 1 who presented with vaginal spotting at $8+4$ weeks of gestation. The patient had given birth vaginally (by vacuum extraction) one year previously, and there were no irregularities in her medical history; in particular, she had no history of sexually transmitted infection or previous abdominal/pelvic surgery. Further examination found no other complaints and no abdominal pain; the patient was hemodynamically stable. Initial serum $\beta$-HCG was 6615 IU/l. Transvaginal ultrasound found no evidence of intrauterine pregnancy, no fluid in the cul-de-sac, and a right-sided adnexal mass with a diameter of approximately $2 \mathrm{~cm}$. Clinical and radiological findings were suggestive of ectopic tubal pregnancy. After discussing all the findings, the patient gave her informed consent to laparoscopic exploration. Bilateral ectopic tubal pregnancy was diagnosed at laparoscopy. The right fallopian tube was found to contain a mass in the isthmic part measuring $20 \mathrm{~mm}$ ( $\bullet$ Fig. 2). The left fallopian tube also showed a mass, measuring $10 \mathrm{~mm}$, with extension in the ampullary region, similarly suspicious for ectopic tubal pregnancy ( Fig. 1). Both masses were unruptured ( Figs. 1 and 2).

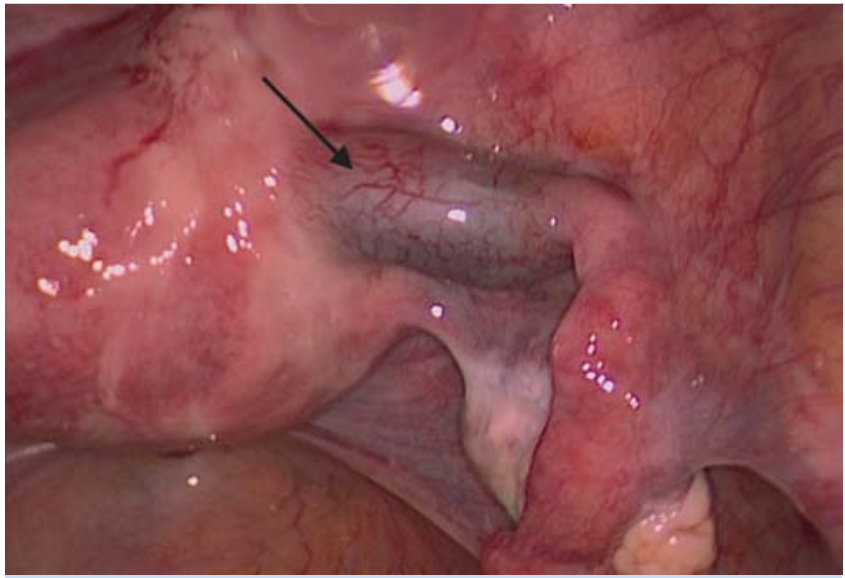

Fig. 2 Findings in the right fallopian tube $(\uparrow)$ of our patient during laparoscopy (UFK Tübingen).

A small amount of blood was additionally found in the cul-de-sac. Because the ectopic pregnancies were still unruptured, bilateral linear salpingotomy was performed to preserve fertility. The pathological report confirmed the diagnosis of bilateral ectopic pregnancy, and the postoperative course was uneventful. Serum $\beta$-HCG had dropped to normal levels at 4 weeks after surgery.

\section{Discussion}

Bilateral tubal ectopic pregnancies are rare, occurring only in around 1 of 200000 pregnancies. They have a great potential to cause maternal mortality and morbidity [1,3]. Between 1989 and 2008, 17 cases associated with various treatments for infertility or assisted reproductive techniques (ART) were reported. In recent years there has been a 3-fold increase due to the rapid growth in the number of women undergoing assisted reproductive techniques. This has also resulted in a rise in bilateral tubal pregnancies. The reported incidence of ectopic pregnancy after in vitro fertilization (IVF) ranges from 2.1 to 9.4 of all clinical pregnancies $[4,5]$. Patients with a familial history of twinning and previous use of fertility drugs are considered to be at higher risk [3]. Irrespective of whether the ectopic pregnancy is spontaneous or induced, good management includes early presentation, a high index of suspicion, detailed ultrasound scan, careful intraoperative inspection of the contralateral tube, histological verification of specimens, and appropriate patient counseling [6]. There have been significant improvements in the prevention and therapy of sexually transmitted infections in recent decades, and this is likely to have had a positive impact on the incidence of spontaneous bilateral tubal pregnancy.

Several theories have been postulated regarding the etiology of bilateral tubal ectopic pregnancy, with one proposed mechanism being the transperitoneal migration of trophoblastic cells [7]. Foster et al. suggested that bilateral tubal pregnancy requires multiple ovulations to occur, the oocytes to be fertilized and the oocytes to implant at sites of tubal damage [8]. Another theory describes a mechanism for superfetation, i.e., fertilization and development of a second oocyte in an already pregnant woman [7, 9].

Interestingly, studies have shown that approximately half of all women with ectopic pregnancies do not have any known risk fac- 
tors [10]; this was most likely also the case in our patient. Although technological changes including ultrasound examination and laparoscopy have contributed to an earlier and more accurate diagnosis of ectopic pregnancy, the presented case demonstrates how challenging this still can be $[11,12]$.

It is difficult to diagnose bilateral ectopic pregnancy before surgery. Usually the diagnosis is made intraoperatively; measurement of $\beta$-hCG levels is not particularly useful $[1,13]$. Indeed, most often the contralateral ectopic pregnancy is asymptomatic or difficult to differentiate from the pelvic pain secondary to medical treatment or to controlled ovarian hyperstimulation [11]. Ultrasound can detect ectopic pregnancy in about $90 \%$ of cases [13]. One study reported that transvaginal sonography showed adnexal abnormality in nearly $95 \%$ of cases with ectopic pregnancies; the most common finding (> 50\%) was nonspecific adnexal mass [13], as was also the case in our patient. A tubal ring without a yolk sac is found in approximately $25 \%$ of cases [13].

The management of tubal ectopic pregnancies can be medical or surgical, and largely depends on the condition of the fallopian tubes at the time of diagnosis. The main challenge is to identify and treat cases of ectopic pregnancy with the potential to cause serious morbidity or death as early as possible, while minimizing interventions in cases which can be resolved without surgical intervention [14].

Nevertheless, surgical intervention is usually required, with medical treatment of ectopic pregnancy reserved for special cases [14]. One study described the use of combined ultrasoundguided local injection of potassium chloride or methotrexate (MTX) and systemic MTX as an efficient non-surgical option for women with tubal pregnancy, high serum $\beta$-hCG concentrations, and fetal cardiac activity [14]. Another study described a combination of uterine artery MTX infusion and embolization with systemic MTX as an effective and safe treatment for non-tubal ectopic pregnancies in women who were still trying to conceive [15].

Tubal ectopic pregnancy can be treated surgically by salpingectomy (removal of the affected fallopian tube) or salpingotomy (preservation of the affected tube) [2]. Despite the potentially increased risks of persistent trophoblast and repeat ectopic pregnancy, salpingotomy is often preferred over salpingectomy because preservation of both tubes is assumed to offer better fertility prospects, although little evidence exists to support this assumption [2].

Spontaneous bilateral tubal pregnancy is very rare. If there is a suspicion of spontaneous tubal pregnancy, laparoscopy with close examination of both fallopian tubes is essential. Any suspicious mass must be removed, and pathological examination is needed to exclude bilateral ectopic tubal pregnancy. One case report has discussed the use of salpingectomy in cases with tubal rupture, with bilateral conservative surgery performed in cases with unruptured ectopic tubal pregnancy [16] as was done in our patient. Salpingotomy is preferable when the tubes have remained intact, but fertility rates drop following previous ectopic pregnancy and may worsen even more if there is a prior history of fertility-reducing factors.

A multicenter, international, randomized controlled trial enrolled women aged 18 years and above with laparoscopically confirmed tubal pregnancy and a healthy contralateral tube, and showed that salpingotomy does not significantly improve fertility prospects compared with salpingectomy [2]. Early presentation allows timely diagnosis prior to tubal rupture, along with man- agement options that encourage tubal conservation and the preservation of fertility.

Recurrent ectopic pregnancies occur in $6-16 \%$ of women with a previous history of ectopic pregnancy. It has been observed that many women, for unknown reasons, fail to conceive even after successful reconstructive tubal surgery. Counseling is therefore very important. One study examined groups with ectopic tubal pregnancy and successful salpingotomy vs. salpingectomy for unilateral ectopic tubal pregnancy and found comparable rates of repeat ectopic tubal pregnancies in both groups [2]. Further studies are needed to investigate the impact of surgical management on subsequent pregnancies in these patients. Existing studies underline the need for a good case selection.

Despite the rarity of bilateral extrauterine pregnancy, the case described here underscores the importance of identifying and closely examining both tubes at laparoscopy. Bilateral conservative surgery is possible in cases with unruptured ectopic tubal pregnancy. The goal in bilateral ectopic pregnancy is to prevent tubal damage during conservative surgery of the fallopian tube. The appropriate surgical procedure after an incidental finding of unilateral or bilateral ectopic pregnancy must be considered in these patients, and the choice of fertility-preserving surgery must be weighed against the increased risk of recurrence.

\section{Conclusions for Practice \\ $\nabla$}

Although ectopic tubal pregnancy is seen more often in patients undergoing assisted reproductive techniques, it is important to be aware that this rare and potentially fatal condition can also occur in patients who do not present with any risk factors. Laparoscopic surgery is effective to confirm the diagnosis and treat heterotopic pregnancies [17]. Further studies are required to investigate whether unilateral or bilateral conservative fertility-preserving surgery is more appropriate.

\section{Conflict of Interest \\ $\nabla$}

The patient gave her informed consent and agreed to the publication of the manuscript. All authors state that they have no conflicts of interest.

\section{References}

1 Andrews J, Farrell S. Spontaneous bilateral tubal pregnancies: a case report. J Obstet Gynaecol Can 2008; 30: 51-54

2 Mol F, van Mello NM, Strandell A; European Surgery in Ectopic Pregnancy (ESEP) study group. Salpingotomy versus salpingectomy in women with tubal pregnancy (ESEP study): an open-label, multicentre, randomised controlled trial. Lancet 2014; 383: 1483-1489

3 Fishback HR. Bilateral simultaneous tubal pregnancy. Am J Obstet Gynecol 1939; 37: 1035

4 Shavit T, Paz-Shalom E, Lachman E et al. Unusual case of recurrent heterotopic pregnancy after bilateral salpingectomy and literature review. Reprod Biomed Online 2013; 26: 59-61

5 Ghaffari F, Eftekhari Yazdi P, Kiani K. A case report of bilateral tubal ectopic pregnancy following day 5 embryo transfer. Arch Med Sci 2011; 7: 1087-1088

6 Eze JN, Obuna JA, Ejikeme BN. Bilateral tubal ectopic pregnancies: a report of two cases. Ann Afr Med 2012; 11: 112-115

7 Tabachnikoff RM, Dada MO, Woods RJ et al. Bilateral tubal pregnancy. A report of an unusual case. J Reprod Med 1998; 43: 707-709

8 Foster HM, Lakshin AS, Taylor WF. Bilateral tubal pregnancy with vaginal delivery. Obstet Gynecol 1982; 60: 664-666 
9 Baijal $N$, Sahni $M$, Verma $N$ et al. Discordant twins with the smaller baby appropriate for gestational age-unusual manifestation of superfoetation: a case report. BMC Pediatr 2007; 7: 2

10 Barnhart KT, Sammel MD, Gracia CR et al. Risk factors for ectopic pregnancy in women with symptomatic first-trimester pregnancies. Fertil Steril 2006; 86: 36-43

11 Creanga AA, Shapiro-Mendoza CK, Bish CL et al. Trends in ectopic pregnancy mortality in the United States: 1980-2007. Obstet Gynecol 2011; 117: 837-843

12 Chopra S, Keepanasseril A, Suri V et al. Primary omental pregnancy: case report and review of literature. Arch Gynecol Obstet 2009; 279: 441-442

13 Frates MC, Doubilet PM, Peters HE et al. Adnexal sonographic findings in ectopic pregnancy and their correlation with tubal rupture and human chorionic gonadotropin levels. J Ultrasound Med 2014; 33: 697-703
14 Wang M, Chen B, Wang J et al. Nonsurgical management of live tubal ectopic pregnancy by ultrasound-guided local injection and systemic methotrexate. J Minim Invasive Gynecol 2014; 21: 642-649

15 Krissi H, Hiersch L, Stolovitch $N$ et al. Outcome, complications and future fertility in women treated with uterine artery embolization and methotrexate for non-tubal ectopic pregnancy. Eur J Obstet Gynecol Reprod Biol 2014; 182 C: 172-176

16 Becker S, Solomayer E, Hornung R et al. Optimal treatment for patients with ectopic pregnancies and a history of fertility-reducing factors. Arch Gynecol Obstet 2011; 283: 41-45

17 Fukuda T, Inoue H, Toyama Y et al. Bilateral tubal and intrauterine pregnancies diagnosed at laparoscopy. J Obstet Gynaecol Res 2014; 40: 2114-2117 